\title{
Heavy Vehicle Propulsion Materials: Recent Progress and Future Plans
}

\author{
D. Ray Johnson \\ Oak Ridge National Laboratory \\ Sidney Diamond \\ U.S. Department of Energy
}


SAE routinely stocks printed papers for a period of three years following date of publication. Direct your orders to SAE Customer Sales and Satisfaction Department.

Quantity reprint rates can be obtained from the Customer Sales and Satisfaction Department.

To request permission to reprint a technical paper or permission to use copyrighted SAE publications in other works, contact the SAE Publications Group.

This article was prepared as an account of work sponsored by an agency of the United States

Government. Neither the United States Government nor any agency thereof, nor any of their employees, makes any warranty, express or implied, or assumes any legal liability or responsibility for the accuracy, completeness, or usefulness of any information, apparatus, product, or process disclosed, or represents that its use would not infringe privately owned rights. Reference herein to any specific commercial product, process, or service by trade name, trademark, manufacturer, or otherwise does not necessarily constitute or imply its endorsement, recommendation, or favoring by the United States Government or any agency thereof. The views and opinions of authors expressed herein do not necessarily state or reflect those of the United States Government or any agency thereof.

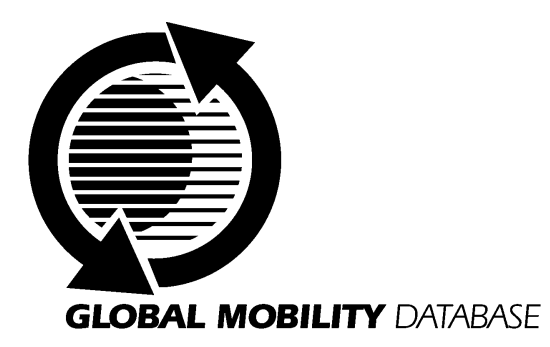

All SAE papers, standards, and selected books are abstracted and indexed in the Global Mobility Database

ISSN 0148-7191

No copyright is asserted in the works of U.S. Government employees.

Positions and opinions advanced in this paper are those of the author(s) and not necessarily those of SAE. The author is solely responsible for the content of the paper. A process is available by which discussions will be printed with the paper if it is published in SAE Transactions. For permission to publish this paper in full or in part, contact the SAE Publications Group.

Persons wishing to submit papers to be considered for presentation or publication through SAE should send the manuscript or a 300 word abstract of a proposed manuscript to: Secretary, Engineering Meetings Board, SAE.

\section{Printed in USA}




\title{
Heavy Vehicle Propulsion Materials: Recent Progress and Future Plans
}

\author{
D. Ray Johnson \\ Oak Ridge National Laboratory \\ Sidney Diamond \\ U.S. Department of Energy
}

No copyright is asserted in the works of U.S. Government employees.

\begin{abstract}
The Heavy Vehicle Propulsion Materials Program provides enabling materials technology for the U.S. DOE Office of Heavy Vehicle Technologies (OHVT). The technical agenda for the program is based on an industry assessment and the technology roadmap for the OHVT. A five-year program plan was published in 2000. Major efforts in the program are materials for diesel engine fuel systems, exhaust aftertreatment, and air handling. Additional efforts include diesel engine valve-train materials, structural components, and thermal management. Advanced materials, including hightemperature metal alloys, intermetallics, cermets, ceramics, amorphous materials, metal- and ceramicmatrix composites, and coatings, are investigated for critical engine applications. Selected technical issues and planned and ongoing projects as well as brief summaries of several technical highlights are given.
\end{abstract}

\section{INTRODUCTION}

The history of the Department of Energy's Office of Heavy Vehicle Technologies (OHVT), along with the overall goals and approach of the office, is discussed elsewhere. ${ }^{1-2}$ The primary goals of the Office are as follows:

1. Develop by 2002 the diesel engine enabling technologies to support large-scale industry dieselization of light trucks, achieving a 35\% fuelefficiency improvement over equivalent gasoline-fueled trucks;

2. Develop by 2004 the enabling technology for class $7-8$ trucks with a fuel efficiency of $10 \mathrm{mpg}$ at $65 \mathrm{mph}$ to meet prevailing emission standards, using either diesel or a liquid alternative fuel;
3. Develop by 2004 diesel engines with fuel flexibility and a thermal efficiency of $50 \%$ with both liquid alternative fuel and dedicated gaseous fuel.

An assessment of technical barriers to the goals of OHVT identified a number of materials issues. ${ }^{2}$ Materials R\&D needs were further addressed in a workshop held in Knoxville, Tennessee, in August 1999 and summarized in recent publications..$^{3-4}$ Comments were solicited from the stakeholders and partners in this program on goals and technical plans for the period FY 2000 - 2004. Approximately 40 people participated in the workshop, representing DOE, DOD/TACOM, the diesel engine manufacturers, materials suppliers, universities, and national laboratories. A web site ${ }^{5}$ was created that includes the 5-year program plan, technical highlights of the program, and future R\&D plans.

\section{MATERIALS R\&D REQUIREMENTS}

Various types of advanced materials are needed to meet the goals of the diesel engine industry and DOE. Materials are chosen for development in the program by means of technology pull; that is, by the requirements of diesel engine industry to meet the technical and programmatic goals of OHVT. Relevant materials include the following: high-temperature alloys, intermetallic alloys, cermets, ceramics, bulk amorphous metals, ceramic and metal-matrix composites, and thermal-barrier and wear coatings.

The most demanding diesel engine subsystems in terms of materials requirements are (1) fuel systems, (2) exhaust aftertreatment, and (3) air handling. These subsystems represent a large fraction of the expected cost of advanced diesel engines.

\section{FUEL SYSTEMS}

The electronic fuel injectors on heavy-duty diesel engines operate at high pressure, $\sim 20,000 \mathrm{psi}$, in order to 
minimize particulate emissions. That pressure requirement is likely to increase to as much as $35,000 \mathrm{psi}$ to meet emerging emissions regulations. High-pressure fuel injection results in problems with wear and scuffing of fuel-injector plungers and erosion, wear, and fatigue of fuel-injector nozzles. In addition, low-sulfur fuels typically do not lubricate the fuel-injector components as well as current diesel fuel, and the ultra-low sulfur fuels expected in the near future may increase the need for wear- and scuff-resistant materials.

Fuel injectors are highly precise systems. The individual components must fit together with clearances sometimes smaller than $1 \times 10^{-6}$ meters. In addition, control of the combustion process requires precise control of the size, shape, and surface finish of the injector components. To maintain quality, therefore, improved manufacturing and inspection methods for the injector components are needed as well as improved materials.

Although a single fuel-injection event occurs in a brief fraction of a second, greater control of the rate and timing of the injection event is necessary to improve the control of combustion and resulting efficiency and emissions. Pilot injection, for example, has been shown to reduce NOx by spreading out the combustion event over time, thus reducing the maximum combustion temperature. Further reductions in NOx might be realized by spreading out the injection into several events, all of which must occur within a very brief time. The current systems for reliably controlling multiple injections are limited by the ability of mechanical and electronic systems to respond precisely and quickly enough to provide the additional control of injection. Smart materials, such as piezoelectric and magnetostrictive materials offer the potential of better control of fuel injection, but a number of improvements in the materials and manufacturing methods for the materials are still needed.

\section{EXHAUST AFTERTREATMENT}

The reduction of NOx and particulate emissions, of critical importance to the OHVT program, is highly materials dependent. Significant reductions in exhaust emissions will require improvements in engine design, advanced and integrated exhaust-control technologies, and improved fuel quality. Advanced engine-control technology may require quantitative real-time NOx sensors and particulate matter (PM) sensors.

Durability of exhaust aftertreatment systems in heavy vehicles is a concern. Lifetimes of at least 500,000 miles are expected, and 1,000,000 miles is desired (compared with 100,000 miles for automobiles). Exposure of the aftertreatment systems to high temperature, vibration, erosion, and chemical attack by species in the oil and fuel will result in degradation of performance. Characterization of the effects of exposure in service on the microstructure and microchemistry of the aftertreatment systems will be needed and may lead to development of more durable systems.

In addition to the emissions regulated by the EPA, such unregulated emissions as $\mathrm{N}_{2} \mathrm{O}, \mathrm{H}_{2} \mathrm{~S}, \mathrm{COS}, \mathrm{NH}_{3}$, and polyaromatic hydrocarbons (PAHs) are becoming increasingly important. The effect of exhaust aftertreatment systems on unregulated emissions will have to be determined and quantified and steps taken to minimize the unregulated emissions.

Relevant exhaust aftertreatment technologies include the following: ${ }^{4}$

- Lean NOx catalysts

- NOx absorbers

- Selective catalytic reduction (SCR)

- Oxidation catalysts

- Particulate matter filters

- Plasma-assisted catalysts

- NOx sensors

- PM sensors

High-priority $R \& D$ issues include cost, durability, and conversion efficiency of lean NOx catalyst systems; loss of conversion efficiency of catalysts and traps due to poisons such as sulfur; loss of conversion efficiency due to thermally induced coarsening of catalyst clusters; fuelefficiency penalty of fuel use as a reductant in SCR catalyst systems; and regeneration and back-pressure issues in PM filters.

\section{AIR HANDLING}

Turbocharging and associated air-handling equipment are important elements of engine control for heavy-duty diesel engines. Advanced engines will place new demands on the air-handling system. Exhaust-gas recirculation (EGR) will likely be required to meet 2002 emission requirements. EGR introduces problems with corrosion of heat-exchanger components for EGR cooling and makes it necessary to increase the turbocharger boost in order to maintain the necessary oxygen partial pressure in the combustion chamber. Therefore, corrosion-resistant materials for EGR coolers will be needed. Also, the additional heat of compression will push conventional aluminum compressor materials to temperatures at which creep deformation will be a problem, and highertemperature compressor alloys will be necessary. Because EGR will require valving and controls, corrosionresistant materials for EGR valves will be needed.

Advanced engine-control strategies require continuous control of the inlet air pressure, making variable-geometry turbochargers and continuously variable wastegate valves necessary. The linkage that controls the variablegeometry turbocharger inlet and wastegate valve operates at high temperature (up to $600^{\circ} \mathrm{C}$ ) and without liquid lubrication. Better materials are needed for the linkage. 
In addition, the inertia of the turbocharger limits the ability of the system to respond as rapidly as desired. Lower mass materials for turbocharger rotors are needed.

Exhaust-gas recirculation will likely increase the overall temperature of the engine hot section and exhaust path. The exhaust manifold and turbocharger housing will be subjected to high thermal loads as well as oxidation and corrosion conditions. Research is needed to develop cost-effective alloys for exhaust manifolds and turbocharger housings.

Air handling represents a significant fraction of the cost of a heavy-duty diesel engine. The performance requirements referenced above must be met with costeffective materials and manufacturing methods.

\section{TECHNICAL HIGHLIGHTS}

\section{INTERMETALLIC-BONDED CERMETS}

The goal of this task is to develop high-strength, hightoughness materials that can be sintered to near net shape for diesel engine applications, specifically for fuel-delivery systems and wear components (e.g., valve seats and turbocharger components). Coordinated activities are conducted at Cummins Engine Co., ORNL, and Southern Illinois University at Carbondale. Requirements for these materials include a minimum hardness of $11 \mathrm{GPa}$ and a thermal expansion coefficient of up to $12 \times 10^{-6} /{ }^{\circ} \mathrm{C}$ at temperatures ranging from $25^{\circ}$ to $800^{\circ} \mathrm{C}$ to minimize thermal mismatch with metallic alloys. The material should also have excellent corrosion resistance in a diesel engine environment, flexure strength greater than $700 \mathrm{MPa}$, and fracture toughness greater than $10 \mathrm{MPavm}$ to ensure long-term reliability. The material should also be compatible with steels and not cause excessive wear of the steel counter face. The upper temperature limit for fuel-delivery systems applications is $540^{\circ} \mathrm{C}$, and for the other wear applications, the limit is $815^{\circ} \mathrm{C}$. Finally, the total processing costs for these advanced materials should be competitive with competing technologies such as TiN or other ceramic coatings on high-speed tool steels.

Preliminary wear testing indicated that improved wear resistance of the cermets could be achieved by decreasing the grain size of the TiC. Achieving fine grain size with the high binder contents is difficult because of the large inter-grain distances. In addition, it is expected that changing the TiC grain shape from a highly faceted one to a more-rounded, equiaxed grain will reduce localized stress at sharp corners. This, in turn, will improve abrasion resistance from any wear debris. Consequently, grain-size refinement is being studied. Several approaches can be used to control the final TiC grain size. The methods being studied in this effort include: (1) use of additives to change the interface behavior of the growing TiC grains, and (2) reduction of the initial TiC particle size. Attritor milling of commercial TiC powders has been used successfully to fabricate fully dense $\mathrm{TiC}-\mathrm{Ni}_{3} \mathrm{Al}$ cermets with submicron TiC grain sizes by pressureless sintering. Efforts are underway to develop a low-pressure injection-molding process for forming complex shapes.

Related efforts in fuel-injector plunger materials include novel forming and machining processes and development of improved zirconia ceramic plunger materials for higherperformance applications. A photograph of typical ceramic and cermet components is shown in Fig. 1.

\section{SMART MATERIALS FOR FUEL SYSTEMS ACTUATORS}

The term smart materials has been widely used to describe materials that have both sensing and actuator capabilities. Prominent among these materials are piezoelectric materials. A project is conducted at Detroit Diesel Corporation and supported by ORNL for development of smart materials for fuel systems applications.

Applications involve the use of piezoelectric materials in fuel-systems actuator functions, in which precise, fast, and controlled displacement is needed. Depending on the selection of the smart material and the type of actuator, displacements ranging from micrometer to millimeters are possible, at response speeds of $0.1 \mathrm{~ms}$ and faster. This compares with those of the fastest electric actuator, which exhibits a response time of $100 \mathrm{~ms}$, for typical millimeter displacements. The bottom line is that actuators made through proper design from various smart materials can have 1000 -fold higher speeds than equivalent electrical devices.

Besides speed, the primary issues for implementing smart materials into actuators for diesel engines are cost, reliability, ease of manufacture, and cycle lifetime of the actuator. The most important is the high cost of many of the actuators which is related to the manufacturing. To date, most actuator designs have been multilayer devices, which require electroding of each surface with of up to 200 layers of ceramic material, along with making electrical connections between layers and to the power supply. Alternate actuator designs are under consideration to lower the costs associated with these complex actuators.

A second source of the high cost associated with piezoelectric actuators is the cost of the electrode materials. The silver-palladium electrodes commonly used for current piezoelectric devices are expensive and thus cost-prohibitive. Nickel and copper electrodes are desirable, but piezoelectric ceramic elements that can be fired to around $900^{\circ} \mathrm{C}$ in non-oxidizing conditions are needed before copper and nickel can be used. Research projects are underway to find new piezoelectric compositions that can be sintered at lower temperatures in inert atmospheres.

Besides cost, another problem associated with prototype piezoelectric actuators is their long-term reliability and durability. Since the fatigue of piezoelectric devices has been found to be associated with the electrode-ceramic 
interfaces within actuator devices, work needs to be done on alternate electrode-ceramic materials combinations.

The final major problem associated with piezoelectric materials is the presence of lead in the materials, such as the most commonly used PZT (lead zirconate titanate) and PMN (lead magnesium niobate) compositions. The presence of lead increases the cost associated with fabrication of the devices, because special handling conditions are required for lead compounds and in the recycling of the materials after use.

ORNL is investigating the processing and corresponding properties of PZT materials and has developed a PZT composition that can be sintered at a relatively low temperature, $930^{\circ} \mathrm{C}$, in an air atmosphere. This property facilitates the use of lower-cost silver electrode materials and reduces the vaporization of lead during sintering.

In parallel with materials development, testing and characterization of piezoelectric stacks and systems have been conducted. A novel smart electronic unit injector has been designed by Detroit Diesel Corporation and successfully engine tested (Fig. 2).

\section{CHARACTERIZATION OF CATALYST MICROSTRUCTURES AND DEACTIVATION MECHANISMS}

The objective of this research is to use analytical and high-resolution transmission electron microscopy (TEM) to characterize the microstructures of emission control catalysts. Catalyst research places emphasis on relating microstructural changes to performance of diesel NOx reduction catalysts. This research is focused on understanding these changes through TEM studies of experimental catalyst materials reacted in an ex-situ catalyst reactor system especially constructed to allow appropriate control of the reaction conditions and the transfer of the sample between reactor and microscope.

Transmission electron microscopy and scanning transmission electron microscopy (STEM) are used to determine the effect of aging on the surface structure and the dispersion of metal-oxide phases supported on alumina. The information derived from these techniques is correlated with probe reactions such as NOx reduction or hydrocarbon combustion to develop a more complete understanding of alumina-supported metal oxide catalysts. These measurements will provide direct information on such chemical and physical properties of the active sites (metal oxides) as crystallinity, dispersion, and morphology of the active component. In addition to studying the fresh catalyst characteristics, the durability of the promising catalyst candidates is also studied. Aging tests are conducted in simulated diesel exhaust conditions. Hydrothermal stability (sintering), carbon deposition (coking), and $\mathrm{SO}_{2}$ tolerance (poisoning) are examined. Changes in the catalyst surface structure and chemistry, as well as the effect of the changes on de-NOx performance, are being characterized to gain an insight into catalyst-deactivation mechanisms.

ORNL and Caterpillar have investigated lean-NOx catalysts that use a hydrocarbon reductant (e.g., diesel fuel) to convert $\mathrm{NOx}$ into $\mathrm{N}_{2}$ and $\mathrm{O}_{2}$. Two of many constraints on such a catalyst are that it achieves a high degree of conversion over a fairly broad temperature range and that the amount of reductant necessary to reach the $70 \%$ goal is sufficiently small as to be cost effective. A number of promising systems comprise either platinum group metals or base metals on oxide supports. Such catalyst systems typically involve near-atomic dispersions, or ultra-fine clusters, of the heavy-metal species on the oxide support. To characterize the microstructure of these materials, techniques such as high angle annular dark-field (Z-contrast) imaging and energy-dispersive spectrometry (EDS) analysis at high collection efficiency, as available on certain dedicated STEMs or TEM/STEM instruments, have proven to be very useful. The application of Hitachi's new HD-2000 dedicated STEM in characterizing such catalytic materials has been reported recently. ${ }^{6}$ The stabilization of ultra-fine clusters to avoid coarsening during service and the resulting loss of catalyst conversion efficiency has been identified as a critical issue in development of durable lean-NOx catalysts.

\section{DEVELOPMENT OF NOx SENSORS}

Recent efforts to improve vehicle fuel economy as well as to reduce emissions have demonstrated he need for a NOx sensor. The NOx sensor is an enabling technology that will promote the advancement of diesel engines by permitting improved engine control along with mandated on-board diagnostics. In addition, NOx sensors are required for new NOx remediation techniques such as selective catalytic reduction by hydrocarbon or urea injection. Ford Motor Company and ORNL have been evaluating prototype NOx sensors from several suppliers and are developing an improved sensor. These sensors are zirconia electrochemical devices employing planar multilayer ceramic (MLC) technology.

These electrochemical sensors are extremely complex devices. This high degree of complexity leads to durability issues as well as low-end sensitivity problems. There are also some problems of selectivity since these devices respond strongly to ammonia (urea) and can be affected by reducing species such as hydrocarbons. Some of these problems arise because of the high processing temperatures $\left(>1500^{\circ} \mathrm{C}\right)$ required to fabricate the ceramic elements. These high temperatures limit the use of more selective electrode materials. To facilitate development of this sensor, new materials compatible with the base materials and processing temperatures need to be developed. The successful development of catalytically selective electrode materials can be used to develop sensors that are selective to an individual gas 
species and that would allow development of more simplistic NOx sensors. The difference in catalytic response between two different electrode materials exposed to the same gas mixture could provide a "differential electrode equilibria" that could be used to selectively measure NOx.

A schematic drawing of the sensor under development is shown in Fig. 3. Recent progress includes development of a high-electrical-resistivity alumina substrate material to reduce cross talk in the device and development of a test rig to measure sensor response time as a function of temperature and NOx concentration and flow rate.

\section{DEVELOPMENT OF LOW-COST AUSTENITIC STAINLESS DIESEL ENGINE COMPONENTS WITH ENHANCED HIGH-TEMPERATURE RELIABILITY}

Diesel engine OEMs must continue to produce advanced large engines with higher fuel efficiency as well as reduced exhaust emissions. The exhaust manifold and turbocharger housing materials must withstand temperatures ranging from 70 to $750^{\circ} \mathrm{C}$ or higher in a normal duty cycle that includes prolonged hightemperature exposure as well as thermal cycling. New technology to reduce emissions such as exhaust gas recirculation (EGR) will push temperatures in these critical components even higher. Current materials like SiMo ductile cast iron would be pushed beyond their current strength and corrosion limits, so new materials like cast austenitic stainless steels are being considered. However, there is no experience and little appropriate high-temperature mechanical properties data available on cast austenitic stainless steel exhaust manifolds, so the purpose of this program is to produce such data and compare the properties with those of SiMo cast iron, particularly for these diesel component applications.

An appropriate commercial baseline cast austenitic stainless steel was identified for evaluation relative to SiMo cast iron. Materials will be evaluated as-cast and after appropriate thermal aging. Tensile, fatigue, and thermal-fatigue properties over a range of temperatures will be evaluated, together with selected high-temperature creep-rupture and oxidation/corrosion testing. Microstructure analysis will be used as needed to understand mechanisms associated with changes in properties and to guide focused alloy modifications for enhanced performance.

To date, the commercial cast iron and baseline $\mathrm{CN}-12$ materials have been obtained, all mechanical-property specimens machined, and all tensile and creep testing of aged and un-aged specimens has been done. Eight small heats (15 lb each) of modified CN-12 austenitic stainless steel have been produced at ORNL and have been evaluated. Preliminary screening of as-cast or aged material with tensile testing and of as-cast material with creep-rupture testing at $850^{\circ} \mathrm{C}$ indicates that significant improvements have been achieved in high-temperature strength and aging resistance (Fig. 4).

\section{FUTURE PLANS}

The ongoing effort to complete the 5-year program plan for Heavy Vehicle Propulsion Materials will continue. R\&D plans will be updated annually, in response to input from the stakeholders in the program. In addition, the program is expected to provide the enabling propulsion materials technology for the planned Twenty-First Century Truck program. $^{7}$

\section{ACKNOWLEDGMENTS}

Research sponsored by the U.S. Department of Energy, Assistant Secretary for Energy Efficiency and Renewable Energy, Office of Transportation Technologies, as part of the Heavy Vehicle Propulsion Materials Program, under contract DE-AC05-00OR22725 with UT-Battelle, LLC.

\section{CONTACT}

D. Ray Johnson, Oak Ridge National Laboratory, P.O. Box 2008, Oak Ridge, TN 37831-6066. Phone: 865/5766832; Fax: 865/574-6098; e-mail: johnsondr@ornl.gov.

\section{REFERENCES}

1. Multiyear Program Plan for 1998-2002, DOE/ORO2071, U.S. DOE, Office of Heavy Vehicle Technologies (OHVT), Office of Transportation Technologies, August 1998.

2. OHVT Technology Roadmap, DOE/OSTI-11690/R1, U.S. DOE, Office of Heavy Vehicle Technologies, Office of Transportation Technologies, February 2000.

3. Diamond, Sidney and D. Ray Johnson, "Heavy Vehicle Propulsion Materials Program," SAE 1999-012254, Government/Industry Meeting, Washington, D. C., April 26-28, 1999.

4. Johnson, D. Ray and Sidney Diamond, "Heavy Vehicle Propulsion Materials Program: Progress and Highlights," SAE Paper 2000-01-2200, Government/ Industry Meeting, Washington, D.C., June 19-21, 2000.

5. Heavy Vehicle Propulsion Materials: http://www.ms.ornl.gov/programs/energyeff/hvpm/defa ult.htm.

6. Blom, D. A., L. F. Allard, B. C. Gates, and P. W. Park, "Catalyst Characterization with the Hitachi HD2000 Dedicated STEM," submitted to Microscopy and Microanalysis, 2001, Invited Paper at Microscopy Society of America 2001, Long Beach, CA.

7. Technology Roadmap for the Twenty-First Century Truck Program: http://www.osti.gov/hvt/21stcenturytruck.pdf 


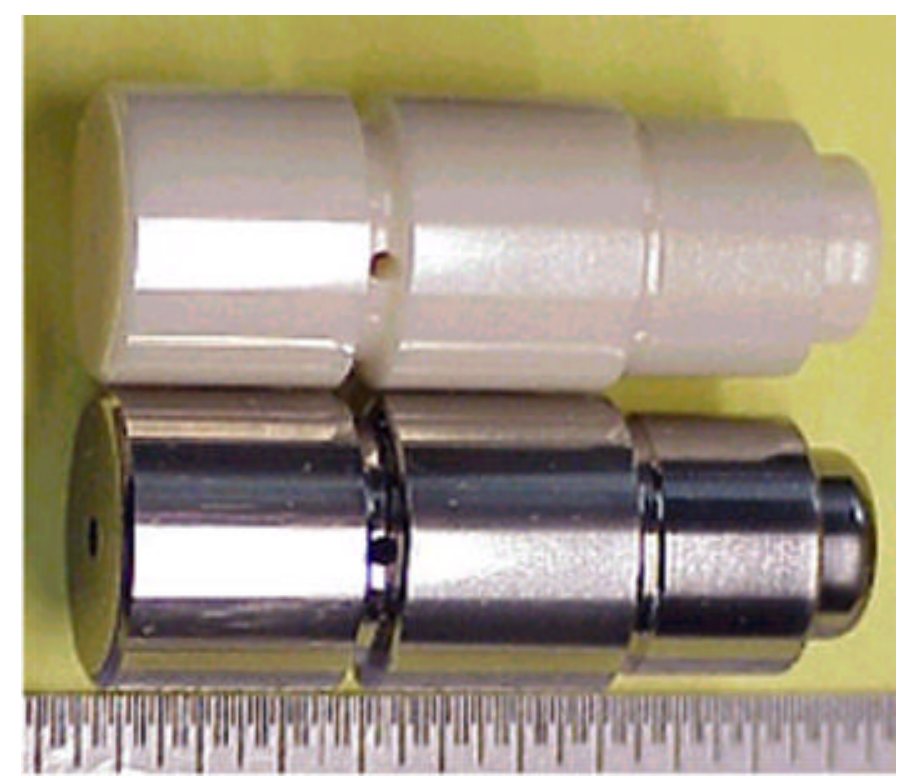

Fig 1. Typical high-performance ceramic (top) and cermet (bottom) fuel injector plungers.

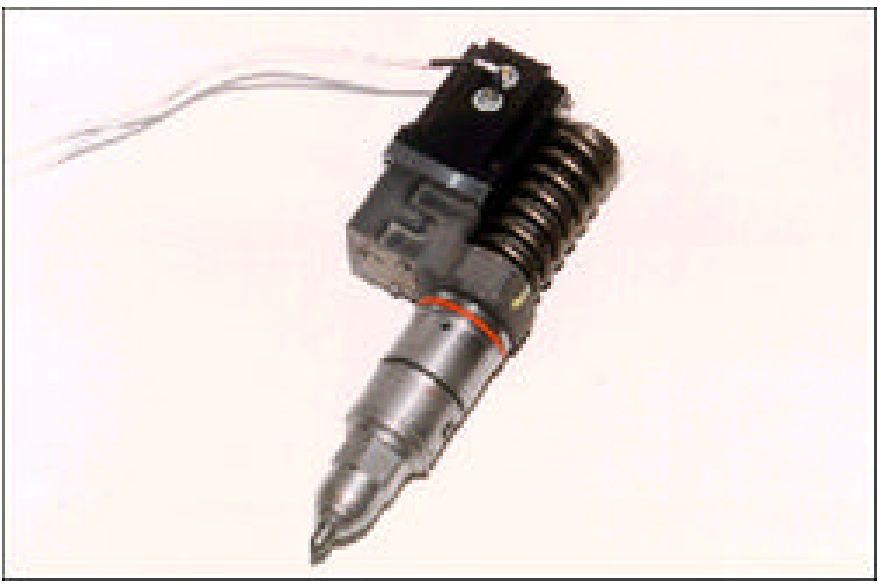

Fig. 2. Electronic Fuel Injector based on smart materials for actuation.

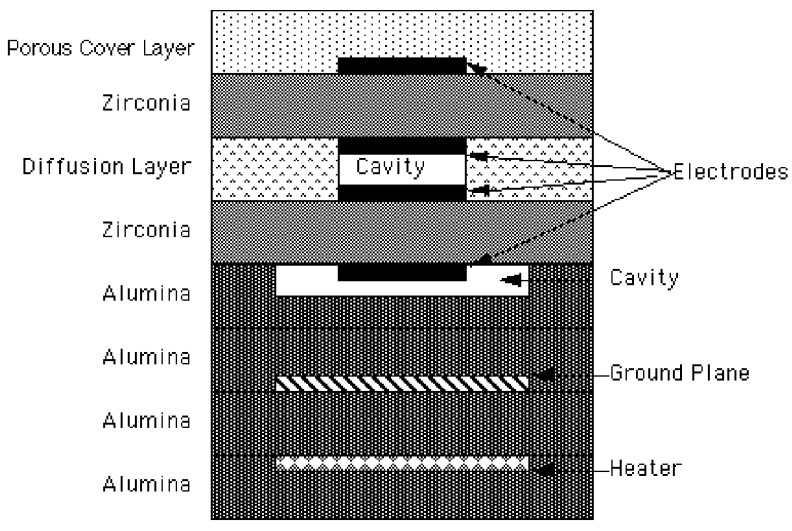

Fig. 3. Schematic drawing on NOx sensor cross section.

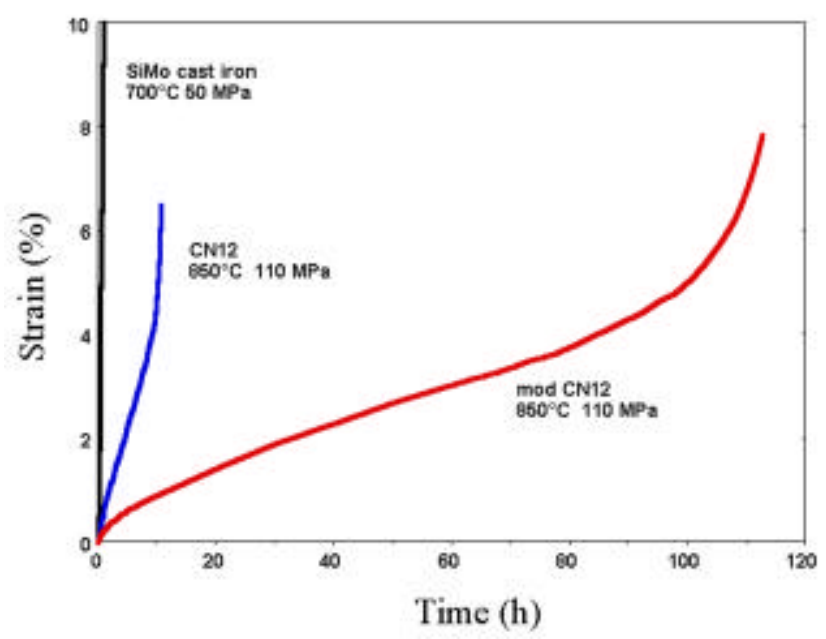

Fig 4. Creep data for cast iron, commercial $\mathrm{CN}-12$ stainless steel, and modified $\mathrm{CN}-12$ stainless steel. 